\title{
Aiming beyond the written, to the writer and writing: The writing consultation as a mentoring process for life-long writing
}

\author{
Collium Banda \\ Unit for Reformational Theology and the Development of the South African Society, Faculty of Theology, North- \\ West University, South Africa \\ E-mail: collium@gmail.com
}

\begin{abstract}
This article critically reflects on how writing centres can address the notion that their primary role is to deal with students struggling with their writing. This critical reflection focuses on the following question: how can writing centres challenge the view that they exist primarily to assist students struggling with or lacking the academic writing skills required at university level? This question is answered from a theoretical framework of writing consultancy as a process of identity change. Presenting the writing consultation as a mentoring process for life-long writing, the article describes the author's experiences of students who viewed the writing centre as a place for students who lack good writing skills. The article further examines some steps that may be taken to de-stigmatise writing centres, and promote them as places of identity change and empowerment. The article envisages that when the writing consultation is viewed as a mentoring process, writing centres may appeal to the greater university population, even students who are competent writers who would normally never see the need to consult writing centres.
\end{abstract}

Keywords: writing consultation; mentoring; writing centres; identity formation; academic socialisation

\section{Introduction}

Writing centres are valuable spaces endowed with the potential to equip university students with skills for life-long writing. The envisioned idea of equipping students with these skills is in line with Austin's (2002) idea of "socialisation", which entails making writing centres function as spaces of enculturating emerging writers in the standards and practices of academic writing. However, this enabling and empowering capacity of writing centres is threatened by the perception that these are spaces for dealing with students who struggle with their writing. This article attempts to dispel this misplaced view by critically reflecting on the following question: How can writing centres challenge the perception that they exist primarily to assist students struggling with the writing skills required at university level? This question arose as a result of my encounters and experiences as a writing consultant for many students, both undergraduate and postgraduate, who dreaded going to the Writing Lab, and seemed to view it as a place aimed at those either overwhelmed by their assignments or those who lacked the 
ability to write academic assignments. I witnessed a number of students who seemed to experience coming to the Writing Lab as humiliating, humbling or something they had been forced into by failure or by their lecturers. Indeed, I recall a few dejected individuals who hated the experience but merely came because it would help them pass their written assignment. I also remember a few cases where lecturers forced their students to visit the Writing Lab by reserving a $10 \%$ mark on the assignment on condition of a visit to this Lab. The Writing Lab personnel had to sign a special slip of paper as proof that the student had visited the Lab for assistance. There were a few occasions where some students frankly pointed out that they had no need for a writing consultation, and had just come for the $10 \%$ grade allocation. Other students registered their displeasure in being coerced to come to the Writing Lab.

Of course, there were many others who found the experience extremely helpful and empowering in terms of their academic writing skills. Some students were pleasantly surprised that the university offered such services free of charge, and realised that they need not suffer alone with the difficulties of academic writing. Many others remarked that they had always passed by the Writing Lab and had always wondered what it was all about, and were glad to finally experience the services of the Lab. Therefore, there is a need for writing centres and their administrators to seriously consider what writing centres should be and do in order to shed the view that they exist primarily to assist students struggling with or lacking the writing skills required at university level.

The next section of this article begins by reviewing literature about the misconceptions of writing laboratories. The section thereafter examines what steps may be taken to de-stigmatise writing centres, and promote them as places of identity change and empowerment. This is followed by a discussion of some aspects which can ensure that writing centres function as mentoring places that equip writers to be life-long writers, and not merely to assist in the creation of well-written essays and assignments. The article envisages that when the writing consultation is viewed as a mentoring process, writing centres may appeal to the greater university population - even students who successfully pass their written assignments, and who would normally never see the need to consult these centres.

\section{The dreaded yet empowering space}

Ever since writing centres came into existence, they have faced many negative perceptions, which means that current negative attitudes and mistrust towards writing centres must not be viewed as entirely new. Carino (1995: 103-104) controversially describes the earliest American writing centres as inadequately staffed, poorly funded outgrowths of English departments at unviersities, frequented by freshmen or delinquent students and, therefore, existing on the periphery of serious academic work done at a university. Waller (2002: 3) states that a much deeper analysis may prove wrong Carino's negative characterisation of early writing centres, but nonetheless acknowledges that at the gist of the many impetuses for the formation of writing centres are "outgrowths of the classroom, sites for re-mediation and/or proficiency work, support for writing across the curriculum programmes, or havens for writers of all kinds". Waller (2002: 9) finds that modern writing centres have gained a positive position, and have moved from the margins to the centre as they "are recognized and accepted on college campuses as advocates of writers of all kinds and at all levels". Concerning the modern state of writing centres, Waller (2002: 9) states that they "have moved from method to site, from margins to the centre". However, with reference to the modern South African tertiary education context, 
Archer and Richards (2011: 8) find that, although many universities now have writing centres, the country's mainstream tertiary education writing centres "do not occupy the 'centre' at all, so much as the margins". In other words, although the modern academy writing centres have some measure of respectable identity, they continue to exist on the margins of the universities.

Some authors highlight that writing laboratories seem to be viewed as places for "laundry" (Boquet 1999: 464) or "a grammar and drill centre, the fix-it shop, the first aid station" (North 1984: 437) attending to symptoms of poor academic skills. This makes writing laboratories appear to function as peripheral, auxiliary, and remedial action centres that attend to students with poor writing skills. Waller's (2002) tracing of the different strands that led to the formation and development of centres in various American universities shows that academic writing remediation has continued to be one of the prominent features in the formation and existence of writings centres. To this end, many writing centres started and grew "as a place to help many students with deficient writing skills" (Waller 2002: 4). A factor that largely contributed to this growth was the adoption by many universities of the "open-admissions policy" (Waller 2002: 4) which meant that some students were admitted into university without the writing skills needed for university writing. This is also true in the South African context, with its history of unequal access to good education for all of its citizens (Archer and Richards 2011, Nichols 2011b). This led to writing centres being viewed as remedial centres for students from disadvantaged backgrounds. From this perspective, the primary role of the writing centre was to attend to deficient writing.

Perhaps an even more startling fact in South Africa is that most tertiary institutions have writing centres but "many people working in these same universities still do not always know what writing centres really do" (Archer and Richards 2011: 8). This not only highlights the mysterious nature of writing centres but also the different and confusing shades with which they present themselves to the public. Archer and Richards' sentiment here shows the possibility that some writing centres may be suffering from an identity crisis resulting in mixed messages to the university public about their role. Archer and Richards (2011: 8-9) concur with North's conclusion that, in real terms, it is easier to describe what writing centres are not rather than what they are because they are premised on pedagogy and a theoretical framework that is vastly different from other aspects of academia.

Some attempts by late $20^{\text {th }}$-century writing centres to self-clarify their own identity, and enhance their appeal and acceptance by the academic public seem to add to the confusion rather than helping to solve it. Summerfield (1988: 9) observes that some writing centres have become too formal, and have added various things to attain a level of comfort that makes them attractive to the wider academic community. She states:

I have visited some writing centres of late. Some astonish me. They are plush, with luxurious carpets, modern (or post-modern) prints on the walls, secretaries, computer terminals, stocked libraries, spacious surroundings and cubicles. I say watch out for cubicles. Watch out for computer terminals. Watch out for all evidence of attempts to break down the gathering of minds.

(Summerfield 1988: 9)

The "plush" that Summerfield refers to is the form of luxurious comfort adopted by some writing centres that aims at lessening the pressure of the meeting of minds by removing 
emphasis from the hard intellectual work of developing writers. While she seems to describe the purpose of this luxurious comfort as the easing or relaxing of the mind so that one can concentrate better on the written text, Summerfield is concerned about the trend of taking the focus off intellectual labour and dialogue, and repositioning this focus on external trappings of comfort, and the conformity with a certain institutional identity. Furthermore, focus is diverted from the person to the text by directing people to look at screens instead of each other, and to work in private in cubicles instead of amongst other writers. This, unfortunately, promotes the impression that writing centres are more concerned with the written texts than with the writers or the writing. This leaves writing laboratories functioning, as already noted above by North (1984: 437), as "laundries" or "fix-it shops" instead of as, one could perhaps say, gyms for improving one's writing stamina. Therefore, it is suggested that writing centres should function as spaces of empowering students to be better writers rather than places for improving written texts. As Archer and Richards (2011: 9), following North, point out, the purpose of writing centres is not to teach language, fix grammar and students or to proofread, but to function as spaces where students learn not only how to produce better writing but also how to become better writers. Therefore, rather than be dreaded as places of remediation, writing centres should be viewed as affable spaces of empowerment.

\section{De-stigmatising writing centres by making them places of change}

One of the greatest challenges faced by writing laboratories is transforming people's incorrect perceptions about them. There is a need for writing centres to create an equipping and empowering impression that enhances their primary role as "place[s] where any members of the university can talk about or read a draft of their written work to an attentive consultant" (Nichols 2011a: 84). An important way in which writing centres can de-stigmatise themselves is by projecting themselves as places of changing identity. As North (1984: 446) rightly asserts, "[if] writing centres are going to finally be accepted, surely they must be accepted on their own terms, as places whose primary responsibility, whose only reason for being, is to talk to writers". However, an essential element of talking to writers includes "[enabling] students to find their own voices in the exclusionary, competitive, and often hostile higher education environment" (Burns, Sinfield and Abegglen 2019: 61).

Ivanič's (1998) significant research highlights the important link between writing and identity formation, and we can infer from this that writing centres should function as places of enabling meaningful writing identity. In concert, Oliveira (2016) highlights writing centres as spaces that can foster the development of a university student's writing identity by providing students with new possibilities of dealing with aspects of academic literacy. However, Oliveira (2016: 29) describes academic writing identity as a new, topical issue in writing studies and writing centre studies that only began to emerge strongly in the 1990s. Until then, the aspect closest to writing identity that received much attention was voice (Oliveira 2016: 29-30). Moreover, Oliveira (2016: 30) finds that, although studies on academic writing identity have increased in recent years, research has not focused much on writing identity in writing centre studies.

Ivanič (1998: 23) presents four aspects of writer identity that she says may frame the reference of people who talk about writing identity. These aspects are the "autobiographical self", the "discoursal self", the "self as author", and the "possibilities for self-hood", all of which she sees as interrelated instead of separate from each other (Ivanič 1998: 24). The "autobiographical self" comprises the historical baggage which every writer carries into their writing, "the 'self' 
which produces a self-portrait, rather than the 'self' which is portrayed" (Ivanič 1998: 24). The "discoursal self" is the impression which the writer consciously or unconsciously conveys about him-/herself in a particular text, and is "concerned with the writer's 'voice' in the sense of the way they want to sound, rather than in the sense of the stance they are taking" (Ivanič 1998: 25). The "self as author" concerns the position taken by the author in a particular writing context, this being "the writer's 'voice' in the sense of the writer's position, opinions and beliefs" (Ivanič 1998: 26). The "possibilities for self-hood" are concerned with the social identities that can be embraced or rejected by the writer, the "prototypical possibilities for selfhood which are available to writers in the social context of writing" (Ivanič 1998: 27). Although this last aspect of writer identity tends to change at a slower rate, the first three aspects change rapidly from one act of writing to another (Ivanič 1998: 27).

Writing centres are challenged to be sensitive to identity formation in the writing process and development of students. As already established by Oliveira, there is limited research on writing identity in writing centre studies. Oliveira (2016: 30) further adds that much focus has been on discourse and narrative, and less on the development of writing identity through writing consultation.

It is significant that Archer and Richards (2011: 6) view writing centres in contexts of historical racial inequality, such as in South Africa, as "uniquely empowering spaces which can contribute to the quest for social equality in ways that few other university structures can". This observation by the authors highlights the potential role of writing centres as leading places of identity change and empowerment. Archer and Richards (2011:6) further highlight that, in South Africa, the emergence of writing centres was in response not just to student writing incompetence but, more importantly, to addressing the effects of the legacy of years of educational deprivation that left students from educationally disadvantaged backgrounds unfavourably compared with their more advantaged peers. The issue of identity is highlighted in their statement below:

These educationally disadvantaged students were often placed in special classes in which the aim was to help them to develop the 'skills' necessary for success at university. However, a result of this educational apartheid was a lingering stigmatisation. The stigma of deficit haunted these students, who were seen as lacking knowledge, skills and even personal qualities that were necessary to academic survival.

(Archer and Richards 2011: 6)

In view of the historical racial division and social inequality in South Africa, one of the main focuses when writing centres originated was liberating and empowering the victims of historical educational inequality to find their voice and identity through writing. There is a need for writing consultants to use this important element of identity change to fight the stigma of writing centres as remedial places.

\section{Writing centres as mentoring centres}

A key process by which writing centres can contribute towards the identity formation of writers is by operating as mentoring centres that place more focus on the writer than on the written text. Mentoring carries the idea of enhancing, equipping, and building one's writing character so that 
one can face the future successfully. Mentoring is used in this article to challenge and reemphasise the need for writing consultants to be people-oriented instead of text-oriented, as well as to challenge the student-public to realise the long-term benefits of writing consultations.

It is not an understatement that academic discourse is a highly specialised practice that students of all abilities and language groups struggle to acquire (Thesen and Van Pletzen 2006, in Archer and Richards 2011: 7). This is an important observation that affirms writing centres as inclusive places not just concerned with written texts but also with the development of their writers. It is envisioned that, when the writing consultation is conducted as a mentoring process, writing centres may appeal to the greater university population including students who easily pass their written assignments and would therefore normally not see the need to consult writing centres. Nichols (2011b) shows that writing centres should aim for an inclusive approach that targets all types of students yet remains focused on writing. The aspect of mentoring means that the consultation process is not merely concerned with the failed or poorly written assignment but also the writer as a life-long writer. As a result, the writing consultation is approached from the higher perspective of enabling, equipping, and empowering the student with skills to be a better writer, and not just to write a good essay to pass a course. Below are some steps that can be taken by writing centres to be mentoring spaces.

\subsection{Functioning as safe places of developing writing skills}

To function as mentoring spaces, it is necessary that writing centres must first be safe spaces for developing the writing skills of writers. The academic world, with its rigorous demands, is a rough world (Burns et al. 2019: 61); perhaps rougher in contemporary times where financial resources are becoming leaner and universities no longer have the luxury of keeping students longer than they intended to stay. Archer and Richards (2011:9) find that South African writing centres "have a strong sense of community and of the value of the individual" which challenge these centres to be "safe space[s], discreet from the harshness of academia" (Archer and Richards 2011: 9). As Nichols (2011b: 22) emphasises, writing centres "need to create a safe space so that students can develop their own agency within the university and beyond". In this, the "aim is to help them make their own informed and unafraid choices" (Nichols 2011b: 22).

It is within a safe context that remains academically grounded, rigorous, and free from the harshness of the academic environment, that students can be mentored to be better writers. For writing centres to be safe places, they must include the aspect of support in order to enable students to freely develop their writing skills without the fear of harsh judgement. Writing centres can be safe places for mentoring by working individually with writers in ways that empower them to develop their own identity and style that allow them to function efficiently and independently.

\subsection{Displaying characteristics that attract all students}

Another important step towards demystifying the uninformed view that writing centres exist primarily to assist students struggling with or lacking the required writing skills is for these places to become visibly inclusive places that focus on writing. Plainly stated, the writing centre must inclusively attract all students. This involves a deliberate step to cater for students who will not naturally consider coming to the writing centres, such as those who easily pass their written assignments or those who already have good writing skills. Nichols (2011b: 21) highlights that, amongst a number of other things, making writing centres attractive places for 
all students involves "creating a new space, with new practices [and] ensuring that the space is seen as non-remedial and not only for a specific types of student". The requirement that it be a new space with new practices means that writing centres need seriously thought-through strategies, and not ad hoc approaches. Making writing centres non-remedial places for all types of students ensures an inclusive space of which the main focus is writing.

\subsection{Equipping the consultants to be agents of identity change}

Most South African writing centres use a peer student-tutor system where mostly postgraduate students are hired as student consultants. This is useful in breaking the hierarchical lecturerstudent relationships in the consultation process. There is a need for student consultants to be adequately equipped by good training in order to be conscientious agents of identity change. The consultation process has its own unique power dynamics that must be seriously considered to make the consultation a space of identity change. The consultants' knowledge of writing and experience in writing consultations make them trusted experts that may tempt them to dominate the consultation process and simply tell the consultee what to do instead of dialoguing with and guiding them to find their competent writing identity. Simultaneously, the consultees' need for help and guidance may lead them to submissively and unreflectively do as guided by the consultants. Therefore, it is important for consultants to know their personal writing identity, and to use it in the consultation process in a non-imposing manner in order to allow the consultees to develop their own identity. Hence, there is a need to equip writing consultants to be agents of identity change in order to make writing centres places of mentoring.

Dowse and Van Rensburg (2011: 160) highlight from various sources that the role of the student consultant in the writing centre is diverse, multiple, political, and contested. They further add that consultants have to negotiate and mediate the uneven power relations that may exist between study supervisor and postgraduate student writer, and - furthermore - the consultant's own position in consultation sessions is questioned and compromised.

Oliveira (2016: 29) pays particular attention to the adoption of writing consultations based on peer-learning by modern writing centres, which he finds is one of the biggest changes in contemporary writing instruction. Embracing Bruffee's insights, Oliveira (2016: 29) states that the writing consultations "removed the hierarchical relation between professor-student common to education settings and introduced a new context of learning based less on teaching and more on dialogue". He (2016: 29) further amplifies Bruffee's elaboration of the three focal points of writing centre consultations, namely (i) respecting the writer's intention (content and writing style), (ii) peer-learning, and (iii) discussion between consultant and writer as a form of learning. This means that the author retains full control of the work while the consultant only plays a suggesting or advisory role without usurping the final authority of the writer. A peerlearning process thus takes away the hierarchical structure of the academy, leaving the consultant and the writer at peer level. That the discussion between consultant and writer is a form of learning emphasises that the focus of the consultation is learning through discussion, not by teaching, which underscores that consultants "do not teach during sessions but instead promote discussions with writers about their writing" (Oliveira 2016: 29). The important role of the consultant is to enable writers to develop their own identity, and not that which the consultant prescribes. The consultant does not impose an identity but makes a space in which the consultee can frame their own identity, and rehearse and develop it. 


\subsection{Understanding the distinction between concentration on the written text and on the writer}

The idea that writing centres must concentrate on equipping writers instead of just making improvements on written texts raises the question of whether it is possible to separate the written text and the writer. Does it mean that concentrating on the author's written text can be done without any effect on the writer's writing? This question can be answered by pointing out that a preoccupation with grammar, language, proofreading, and editing indicates a higher concentration on the written text than on the writer's writing skills. As already noted by North (1984), writing centres are spaces where students learn not only how to produce better writing, but also how to become better writers. This highlights the need for writing consultants to learn to distinguish clearly between what it means to concentrate on the written text and what it means to concentrate on the writer. An important distinction between concentrating on the written text and on the writer is one of empowering, equipping, and building independence within the writer for future writing tasks. This may enhance the appeal of writing centres to those students who may never see the need to come to these centres. It is envisaged that such an approach may challenge university administrators against deploying writing centres into obscure corners, but rather position them in the main centres of the universities as part and parcel of the institution's core learning culture.

\subsection{Approaching student writing consultancy as a process of socialisation into the academy}

The aspect of approaching writing centres as mentoring centres fits in with "the idea that 'literacy' is the mastering of a set of social practices" (Archer and Richards 2011: 7). Such an approach challenges how writing centres recruit and train writing consultants, and also how the centres relate to the students who report to them - the students have not just come to improve their essays; much more, they need to be equipped to be better writers, which entails an element of socialisation into the academy. A significant step towards making writing consultation a mentoring process for life-long writing is to approach writing consultancy as a process of socialisation into the academy. Socialisation can be described as "a process through which an individual becomes part of a group, organization, or community" (Austin 2002: 96). Viewed from Austin's perspective of professional socialisation, writing centres introduce and expose emerging writers to the cultural standards and practices of academic writing at university level. This aspect of socialisation can be viewed as two-pronged: first, it targets the student writing consultants, and second, it targets the students who seek the services of the writing centres.

Socialisation targeted at writing consultants is concerned with the level and breadth of training and equipping, which must aim not just at preparing these consultants for their immediate roles in the writing centres but also as future front-line academics. Austin (2002: 96) highlights that literature on socialisation shows that postgraduate students' access to smaller responsibilities, and not the first appointment to faculty positions, plays a significant role in introducing individuals to the culture of the academy. For some students, working as a writing consultant may be the first step into academic responsibilities or may be the only opportunity before appointment into a fulltime academic post. Therefore, employing postgraduate students as writing consultants must be viewed as a process of socialising emerging academics into the scientific culture, systems, and values of university education. This highlights the significance of places such as writing centres and writing laboratories that employ postgraduate students as student consultants to expose them 
to the skills and expectations of being an academic. Writing centres can function as places for enhancing the professional capacity of the student consultant by viewing themselves as being concerned not just with enhancing the learning of struggling writers but also with the preparation of equipping their student staffers for future careers as academics and researchers.

By way of a personal testimony, while completing my doctoral studies at Stellenbosch University, I worked at this university's Writing Lab. The Writing Lab had a comprehensive approach to writing consultancy in that they catered for students from all of the university's faculties and departments. The training I received for student consultancy enabled me to work with texts from a wide range of academic disciplines meaning that, by the end of the year, I had handled texts from the humanities, sciences, engineering, and economics fields. This comprehensive approach required me to develop a versatile mind, set of ears and eyes, which would be useful beyond my individual specific field of specialisation (Theology). Versatility and usefulness are underscored here to highlight that the student consultant does not need to be an expert in the specific field of the student consultee's research paper or essay, but needs sound knowledge on writing. An understanding of writing equips one to be aware of the requirements and practices of the different academic genres.

Burns et al. (2019) provide an example of how writing centres can socialise students into the academy by their "learning development" model. This model uses the concept of "third space partnerships' with students to train those students who would normally be considered nonuniversity talent to become academics. The idea of "third space" refers to the liminal space between the student and the academy where the student receives extra-curricular training in aspects such as teaching, tutoring, research, designing, and developing learning and policymaking materials (Burns et al. 2019: 61). In their study, Burns et al. reached out to and recruited non-traditional students, and trained them to become academics that would train other nontraditional students to find their feet in the rigorous university education system. According to Gutiérrez (2008: 152), "[in] significant ways, writing centres are third spaces or transformational spaces where the potential for an expanded form of learning and the development of new knowledge [is] heightened". Writing centres can adopt the third spaces or transformational spaces approach which has strong elements of socialising students into the academy, and facilitates identity change.

Writing from the perspective of higher education, Austin, Connolly and Colbeck (2008: 69) call for universities to be places that groom and empower graduate students, especially doctoral students, to handle the full range of roles in the academy. From this perspective, the plea is that student writing consultancy must be viewed as a form of professional socialisation. There is a strong sense in which the use of student consultants or writing consultants must function as a "preparatory experience for the faculty career" (Austin 2002: 96) that exposes them to skills and experiences of the academy environment.

Murray, Morag, Moore and Murphy (2008) view academic writing as a form of behaviour that can be learnt and improved upon to highlight the empowering nature of writing centres. Similarly, it can be said that academic writing is a form of identity change that can be fostered and cultivated through the writing consultation. However, while the resultant identity change should bear the hallmarks of scholarly excellence and academic depth, it should not be an image imposed by the consultants, but rather one that the consultees are guided to build for themselves. 
As already pointed out, this means that the process of training student consultants should seriously include equipping them to be critical agents of identity change.

\section{Conclusion}

This article sought to reflect on the question of how writing centres can demystify the perception that they exist primarily to assist students struggling with the academic writing skills required at university level. This question was answered from the framework of identity change, which entails that writing consultancy is a process that enables students to develop writing skills that allow them to own their identity. The aspect of mentoring means that the consultation process is not concerned just with the failed or poorly written assignment - a writing consultation is approached from the higher perspective of enabling, equipping, and empowering the student with skills to be a better writer. Such an approach places a higher demand on how writing centres recruit and train writing consultants, and also how these centres relate to the students who report to them: the students have not come just to improve their essays - they have come to be equipped to be better writers. This may enhance the appeal of writing centres to competent students who may never see the need to come to these centres. It is envisaged that such an approach may challenge university administrators against deploying writing centres into obscure corners, but rather position them in the main centres of the universities as part of the institution's core learning culture.

\section{References}

Archer, A. and R. Richards 2011. Writing centres as alternate pedagogical spaces. In A. Archer and R. Richards (eds.) Changing spaces: Writing centres and access to higher education. Stellenbosch: Sun Media. pp. 5-15.

Austin, A.E. 2002. Preparing the next generation of faculty: Graduate school as socialization to the academic career. The Journal of Higher Education 73(1): 94-122. https://doi.org/10.1080/ $\underline{00221546.2002 .11777132}$

Austin, A.E., M.R. Connolly and C.L. Colbeck. 2008. Strategies for preparing integrated faculty: The centre for the integration of research, teaching, and learning. New Directions for Teaching \& Learning 2008(113): 69-81. https://doi.org/10.1002/t1.309

Boquet, E.H. 1999. 'Our little secret': A history of writing centres, pre- to post-open admissions. College Composition and Communication 50(3): 463-482. https://doi.org/10.2307/ $\underline{358861}$

Burns, T., S.F. Sinfield and S. Abegglen 2019. Third space partnerships with students: Becoming educational together. International Journal for Students as Partners 3(1): 60-68. https://doi.org/10.15173/ijsap.v3i1.3742

Carino, P. 1995. Early writing centers: Toward a history. The Writing Center Journal 15(2): $103-115$. 
Dowse, C. and W. van Rensburg. 2011. 'Conversations' with postgraduate writers: Understanding the role of the peer consultant. In A. Archer and R. Richards (eds.) Changing spaces: Writing centres and access to higher education. Stellenbosch: Sun Media. pp. 159-167.

Gutiérrez, K.D. 2008. Developing a sociocritical literacy in the third space. Reading Research Quarterly 43(2): 148-164. https://doi.org/10.1598/rrq.43.2.3

Ivanič, R. 1998. Writing and identity: The discoursal construction of identity in academic writing. Amsterdam and Philadelphia: John Benjamins Publishing Company. https://doi.org/ $\underline{10.1075 / \mathrm{swll.5}}$

Murray, R., T. Morag, S. Moore and M. Murphy. 2008. The writing consultation: Developing academic writing practices. Journal of Further and Higher Education 32(2): 119-128. https://doi.org/10.1080/03098770701851854

Nichols, P. 2011a. Student culture and cultural change: A manifesto for writing praxis in a South African writing centre. In A. Archer and R. Richards (eds.) Changing spaces: Writing centres and access to higher education. Stellenbosch: Sun Media. pp. 19-31.

Nichols, P. 2011b. A snowball in Africa with a chance of flourishing: Writing centres as shifters of power in a South African university. In A. Archer and R. Richards (eds.) Changing spaces: Writing centres and access to higher education. Stellenbosch: Sun Media. pp. 91-99. https://doi.org/10.1080/1013929x.1998.9678044

North, S.M. 1984. The idea of a writing center. College English 46(5): 433-446.

Oliveira, D. 2016. The development of writing identity through writing centre tutorial. Transcommunication 3(1): 27-48.

Summerfield, J. 1988. Writing centres: A long view. The Writing Centre Journal 8(2): 3-9.

Waller, S.C. 2002. A brief history of university writing centres: variety and diversity. Available online: http://www.newfoundations.com/History/WritingCtr.html (Accessed 24 November 2018). 